RAE-IC, Revista de la Asociación Española de Investigación de la Comunicación

vol. 8, núm. 15 (2021), 452-468

ISSN 2341-2690

Recibido el 23 de agosto de 2020

DOI: https://doi.org/10.24137/raeic.8.15.23

Aceptado el 15 de diciembre de 2020

(c) (1) (2)

\title{
Reconocimiento, identificación y apropiación de estereotipos femeninos representados en telenovelas ecuatorianas: caso Sharon La Hechicera
}

Recognition, identification and appropriation of female stereotypes represented in Ecuadorian soap operas: the case of Sharon La Hechicera

Silva-Gaviles, Nicole Pontificia Universidad Católica del Ecuador Sede Santo Domingo (PUCESD) cnsilvag@pucesd.edu.ec

Vaca-Rivera, Bryan Pontificia Universidad Católica del Ecuador Sede Santo Domingo (PUCESD) brvacar@pucesd.edu.ec

Arrobo-Agila, Juan Pontificia Universidad Católica del Ecuador Sede Santo Domingo (PUCESD) aajp@pucesd.edu.ec

Bravo-Sánchez, Santiago Pontificia Universidad Católica del Ecuador Sede Santo Domingo (PUCESD) bssp@pucesd.edu.ec

Forma de citar este artículo:

Silva-Gaviles, N., Vaca-Rivera, B., Arrobo-Agila, J. y Bravo-Sánchez-J. (2021). Reconocimiento, identificación y apropiación de estereotipos femeninos representados en telenovelas 
ecuatorianas: caso Sharon La Hechicera. RAE-IC, Revista de la Asociación Española de Investigación de la Comunicación, 8(15), 452-468. https://doi.org/10.24137/raeic.8.15.23

\section{Resumen:}

La telenovela latinoamericana es una representación dramatizada de la realidad, donde el protagonismo es para los personajes femeninos, y que junto a sus características y narrativas construyen e instauran el ideal de mujer. En 2018, la cadena de televisión Ecuavisa estrenó la telenovela Sharon La Hechicera como un homenaje a la cantante Edith Bermeo, víctima de femicidio y constituida como un personaje icónico de la cultura ecuatoriana. El propósito fue identificar los estereotipos femeninos en esta teleserie y analizar la reproducción de conductas de los personajes por parte de la audiencia. El abordaje metodológico fue desde el enfoque mixto y se realizó en tres momentos; el primero, se caracterizó a los personajes femeninos de la telenovela; el segundo, una encuesta aplicada en tres localidades de Ecuador (Quito, Guayaquil y Santo Domingo de los Colorados) y tercero, una entrevista semiestructurada a profundidad con los participantes que vieron la mayor, sino toda, la telenovela. Se empleó una muestra de 300 personas, 100 sujetos por cada sitio. Se identificaron 9 personajes femeninos, siendo Sharon y Santanera los más reconocidos, y 5 estereotipos, destacando "las mujeres deben soportar infidelidades y maltratos de sus esposos para mantener su matrimonio" (48\%), "las mujeres que usan prendas cortas son más fáciles y accesibles" (46\%), y "es necesario que las tecnocumbieras usen ropa pequeña para llamar la atención del público" (44\%). Finalmente, los estereotipos encarnados en los personajes de una telenovela y su visualización permiten la instauración de estos en el imaginario de la audiencia.

Palabras clave: estereotipo femenino, telenovela, Sharon La Hechicera, telenovela ecuatoriana, apropiación de estereotipos. 


\section{Abstract:}

The Latin American telenovela is a dramatized representation of reality, where the protagonism is for the female characters, and together with their characteristics and constructive narratives, they establish the ideal of women. In 2018, Ecuavisa Network premiered the telenovela Sharon La Hechicera as a tribute to the singer Edith Bermeo, victim of femicide and constituted as an iconic character in Ecuadorian culture. The purpose was to identify female stereotypes in this TV series and to analyze the audience's reproduction of character behaviors. The methodological perspective was from the mixed approach and was carried out in three moments; the first, the female characters of the telenovela were characterized; the second, a survey applied in three locations in Ecuador (Quito, Guayaquil and Santo Domingo de los Colorados) and third, an in-depth semi-structured interview with the participants who saw the greatest, if not the entire series. A sample of 300 people, 100 subjects from each site, was used. 9 female characters were identified, such as Sharon and Santanera the most recognized, and 5 stereotypes, highlighting "women must suffer infidelity and mistreatment from their wives to maintain their marriage" (48\%), "women who wear short clothes are easier and accessible "(46\%), and "technocumbieras need to wear small clothes to get the attention of the public "(44\%). Finally, the stereotypes embodied in the characters of a soap opera and their selection allow the establishment of these in the imaginary of the audience.

Keywords: female stereotype, telenovela, Sharon La Hechicera, Ecuadorian telenovela, stereotyping.

\section{INTRODUCCIÓN}

El consumo de los contenidos televisivos en el entorno pueden influir en la construcción social de un individuo. En el caso de Latinoamérica, la telenovela se constituyó como un producto de consumo en la era industrial. Un fenómeno de entretenimiento basado en el melodrama, así es como lo describe Bautista y Dolores (2008); la telenovela ha sido 
encasillada como una forma mediocre de entretener al público. Esto debido a las temáticas que aborda; las diferencias de género, la desigualdad y la violencia. Sus personajes llevan consigo una formación cultural, creados para desarrollar simpatía con el espectador (Caldevilla, 2011). En el caso del género femenino, en la telenovela latinoamericana, ha sido representado como una figura sometida y abnegada o fuerte $y$ activa, considerada perjudicial para el hombre (Hidalgo-Marí, 2018).

En los años setenta, George Gerbner y Larry Gross desarrollaron la "Teoría del Cultivo", la cual señala que mientras una persona esté más expuesta a los contenidos de la televisión, es más propensa a creer que la realidad que observa en los medios es la misma en la que vive (Ahmed Ali, Martín Galán y Nos Aldá, 2011). La teoría formó parte de un proyecto aún más grande, denominado "Indicadores Culturales", que descompone al fenómeno televisivo en tres partes: el productor, el mensaje y el receptor (Álvarez, 2008). Entre los principales resultados de la investigación de Gerbner y Gross fue que los contenidos emitidos por la televisión llevan consigo estereotipos, mismos que pueden ser captados y apropiados por la audiencia. Algunos ejemplos citados son el protagonismo del sexo masculino, que a su vez se trata de hombres profesionales liberales y directivos, la clase alta vista como una "situación deseable", la mujer casada desempeñando roles domésticos o en caso de ser profesionales, serían enfermeras, modelos, secretarias o criadas (Perosanz, del Río Pereda, Álvarez, García, García, Garrachón y Yánez, 1998).

En la presente investigación, el objetivo será identificar si las telenovelas también forman parte del contenido capaz de influenciar a la audiencia. Esto a partir de analizar el reconocimiento, la identificación y la apropiación de estereotipos de los personajes femeninos de la telenovela Sharon La Hechicera en sus espectadores. Uno de los indicadores culturales planteados por la teoría del cultivo son los "mensajes", que según Gerbner llevan contenidos intencionales y otros no intencionales. El reconocimiento de estos mensajes dependerá mucho de quién es el receptor y su capacidad de decodificar el mensaje (Ahmed Ali, Martín Galán y Nos Aldá, 2011). 
El segundo paso en este proceso de análisis de influencia es la "identificación" que tiene el espectador con los personajes de la telenovela. En esta fase es necesario analizar al "productor", otro de los indicadores culturales de Gerbner; que se refiere a las empresas que generan el contenido (García, 2008). Uno de los objetivos de las productoras es crear un efecto de proximidad entre el espectador y la telenovela, para aumentar su consumo. Según Caldevilla (2010), la televisión construye esquemas en sus contenidos, que buscan la identificación con el mayor número de espectadores. La identificación por simpatía tiende a suprimir la distancia entre la audiencia y el personaje (Amigo, Bravo y Osorio, 2014). Sin embargo, ¿Qué es lo que crea simpatía? Pasquier (citado por Amigo, Bravo y Osorio, 2014); señala que este fenómeno se da, en la mayoría de casos, por un tipo de superioridad en su apariencia física. El índice de perfección del personaje lo constituye como modelo.

Finalmente, la apropiación resultaría de una interpretación de los personajes y una identificación con los mismos para adoptar sus conductas. Esta fase está relacionada directamente con el "receptor", como el tercer indicador cultural de Gerbner; mismo que a través de sus características sociales y demográficas se determinará si es capaz o no de asimilar las conductas de los personajes de las telenovelas (Ahmed Ali, Martín Galán y Nos Aldá, 2011). Para Esteban (2013), las personas ya son el producto de mensajes emitidos por los medios, que señalan los estilos corporeidad que alguien debe tener y los comportamientos que deben ser rechazados. Hidalgo-Marí (2017) propone que las narrativas televisivas tienen la capacidad de reestructurar los contenidos estereotípicos clásicos para generar nuevos patrones y tendencias.

En la telenovela latinoamericana, la mujer ha sido relacionada con la belleza, el romanticismo y el hogar; mientras el hombre, con la fortaleza, la sexualidad y el poder. Los personajes son desarrollados conforme a visiones estereotípicas de cada género (Hernández, 2006). Pese a esto existe "otro tipo de mujer", a la que Tatiana HidalgoMarí (2017) ha denominado la "mujer fatal". Se trata de un personaje femenino cautivador, erótico y seductor; que utiliza su atractivo como herramienta de subsistencia y superación. Tanto en el caso de protagonistas y antagonistas, la 
telenovela sirve como un medio para implantar ideales de belleza, que propician discriminación a las mujeres que no los cumplen (Bonavita y de Garay, 2011).

Es así como los mensajes emitidos a través de la telenovela contribuyen a la reproducción de estereotipos de género, introduciéndose en el imaginario colectivo como una normalidad (Pérez y Leal, 2017). Además, es interesante analizar la evolución de estos pensamientos a través del tiempo. Tal como lo propone Hidalgo-Marí (2017), frente al estudio de la construcción de la "mujer fatal" en el discurso de las telenovelas, que ya arroja nuevos significados en la cultura contemporánea. Un ejemplo de la reproducción de estereotipos se ve reflejado en las cirugías plásticas, que se venden con el propósito de que la mujer "pueda cumplir" con los modelos ideales que visualiza a través de la telenovela. "La mujer se sacrifica, hace sufrir a su cuerpo para agradar a otros, se violenta a sí misma para conseguirlo. Esta violencia se justifica, porque lo importante no es que sea quien decide ser, sino que cumpla con el "deber ser" (Bonavita y de Garay, 2011).

En Ecuador, la televisión nacional ha apostado por la producción de telenovelas, documentales, dramatizados y otros formatos de ficción (León y Suing, 2016). En los años ochenta, la cadena de televisión nacional Ecuavisa fue la pionera en realizar series y telenovelas cómicas. Mientras que en el año 2000, TC Televisión se sumó a esta lista (Obitel, 2011). Producciones recientes como Tres familias, La Trinity y El secreto de Toño Palomino tuvieron un alto raiting en el país. Las telenovelas se desarrollaron en ambientes que contextualizan la realidad actual del país, política, económica y social. La mayoría se presentan en barrios de clase media y baja.

Para el 14 de agosto de 2018, Ecuavisa estrena la telenovela biográfica Sharon La Hechicera, con el propósito de recordar la vida de Edith Bermeo, la tecnocumbiera conocida como Sharon La Hechicera. Bermeo fue una guayaquileña, reconocida por ser cantante, actriz, presentadora de televisión, productora musical, diseñadora, imagen de productos publicitarios, entre otros labores. Su música la catapultó como un ícono de la cultura popular ecuatoriana. Además, su estilo se impuso como vestimenta de los grupos dedicados a la tecnocumbia. Por sus prendas cortas y apretadas, Bermeo se puso 
en la mirada de muchas personas que disfrutaron de su música, pero también fue criticada, principalmente por los medios de comunicación.

En un contexto donde Ecuador se encontraba sensible por los altos porcentajes de casos de femicidio y la última reforma del Código Orgánico Integral Penal, murió Edith Bermeo el 4 de enero de 2015 en Santa Elena, en un confuso accidente donde fue acusada su ex pareja Geovanny L., siendo condenado a una pena de 26 años (Metro Ecuador, 21 de junio de 2019). La imagen de una mujer embestida por un vehículo en la vía, sensibilizó a los ecuatorianos, haciendo que Bermeo pase de ser una mujer criticada por su estilo físico, estético y musical, a ser una víctima de las circunstancias violentas y desigualdades que existen en el país. Es así como la cadena de televisión más popular del país produce la telenovela Sharon La Hechicera, dividida en 2 temporadas de 87 y 85 capítulos respectivamente. El melodrama se desarrolló en Guayaquil, en un contexto de vivencia popular, donde se muestran los inicios de la carrera musical de Edith Bermeo, su vida personal, las dificultades e injusticias que atraviesa para alcanzar el éxito a pesar de sus bajos recursos. A pesar de ser una telenovela biográfica, la producción conlleva varias historias y personajes que intentan impedir o catapultar el éxito de Bermeo; personajes caracterizados con estereotipos propios de la cultura ecuatoriana o desarrollados a partir del consumo de televisión nacional o internacional.

En Ecuador no existen investigaciones que abordan la influencia de las series televisivas en la construcción de estereotipos en la audiencia desde sus personajes femeninos. El propósito de este trabajo describe los argumentos sobre la influencia del contenido de las telenovelas en la audiencia ecuatoriana. Es por ello que, se analizaron los procesos de identificación, reconocimiento y apropiación de los estereotipos femeninos presentados a través de los personajes del programa Sharon La Hechicera.

\section{METODOLOGÍA}

Este trabajo se abordó desde el enfoque mixto; porque el proceso para recolección de información, análisis y tipo de datos combinan las perspectivas cuantitativa y cualitativa de investigación (Santos, Pi y Rausky, 2018). Además, es de tipo descriptivo, ya que no 
se construye ninguna situación controlada, sino que se observa el contexto existente entendido desde una reflexibilidad investigativa (Piovani, 2018).

La investigación se realizó en tres momentos: el primero, se identificó los personajes femeninos de la telenovela y su caracterización a través de una matriz de ordenamiento; el segundo, una encuesta aplicada en tres localidades de Ecuador, y tercero, una entrevista semiestructurada a profundidad (Valles, 1999) con los participantes que vieron la mayor, sino toda, la telenovela. El criterio para escoger las ciudades responde a un marcado regionalismo al momento de consumir producciones ecuatorianas, por tanto se seleccionó a Quito (región Sierra), Guayaquil y Santo Domingo de los Colorados (región Costa).

La entrevista se aplicó a una muestra de 300 personas, 100 sujetos por cada sitio. El instrumento se dividió en 3 partes: la primera, datos demográficos del encuestado; la segunda, conocimiento sobre la telenovela y su visualización (en caso de no haber consumo, la encuesta finaliza), y la tercera recoge la percepción acerca del programa, a través de personajes favoritos, estereotipos identificados, mensaje de la telenovela, etc. Del total de participantes, se escogió a 6 individuos que habían visualizado toda la telenovela, para una entrevista a profundidad. Las preguntas de este instrumento se enfocaron en el desarrollo de conductas a partir de la visualización de la serie en los participantes. Estas conductas podrían tratarse de la repetición de frases o comportamientos parecidos a las acciones de los personajes, deseo por imitar a algún personaje o adjudicación de estereotipos a personas de su entorno o a sí mismo. El análisis se realizó a través de la aplicación de tablas de frecuencias y con la frecuencia relativa empleando el programa Microsoft Excel Versión 16.38 (2020).

\section{RESULTADOS}

Se encuestaron a 300 personas, 202 mujeres y 98 hombres. La edad de los espectadores se encuentra comprendida entre los 25 y 40 años, y la mayoría se encuentra en una posición económica de clase media (56\%). Del total de participantes, 174 vieron la telenovela Sharon La Hechicera. 
En la telenovela se identificaron 9 personajes femeninos (ver tabla 1). Todos están construidos sobre la base de prejuicios y signos característicos que los diferencian entre sí y que crean identidad empleando elementos como la ropa, el maquillaje y los significados dados a estos. Por tanto, los factores físicos empleados para estos personajes representan roles dentro del cotidiano en la sociedad ecuatoriana. Además, estos estereotipos responden a cómo la mujer es visualizada por el resto de personajes desde las relaciones de poder, interacciones y tramas, en donde, hay un pronunciado distanciamiento entre las "buenas mujeres" y las "malas mujeres".

Tabla 1. Personajes femeninos identificados en la telenovela Sharon, La Hechicera, características distintivas y estereotipo construido desde su imagen y roles asignados

\begin{tabular}{|c|c|c|}
\hline Personaje & Efecto de auto cumplimiento & Estereotipo identificado \\
\hline Sharon & $\begin{array}{c}\text { Prendas de vestir cortas, } \\
\text { voluptuosidad y forma sensual de } \\
\text { moverse. }\end{array}$ & $\begin{array}{l}\text { Las mujeres que usan prendas } \\
\text { de vestir cortas son "fáciles" }\end{array}$ \\
\hline Santanera & $\begin{array}{l}\text { Rostro demacrado, movimientos } \\
\text { torpes a causa del alcohol, prendas de } \\
\text { vestir ajustadas, colores vivos y } \\
\text { brillantes y forma seductora de } \\
\text { moverse. }\end{array}$ & $\begin{array}{l}\text { Las mujeres "viciosas" llevan } \\
\text { una mala vida. }\end{array}$ \\
\hline La Chonera & $\begin{array}{l}\text { Prendas de vestir cortas, maquillaje en } \\
\text { exceso y de colores vivos. }\end{array}$ & $\begin{array}{l}\text { Las mujeres que usan ropa } \\
\text { Ilamativa y maquillaje excesivo } \\
\text { son "malas" }\end{array}$ \\
\hline Pilar & $\begin{array}{l}\text { Prendas de vestir elegantes, poco } \\
\text { maquillaje y accesorios pequeños y } \\
\text { refinados. }\end{array}$ & $\begin{array}{l}\text { Las mujeres que usan ropa } \\
\text { elegante y accesorios } \\
\text { refinados tienen dinero. }\end{array}$ \\
\hline Tecnocumbieras & $\begin{array}{c}\text { Ropa corta para representar el género } \\
\text { de su música y llamar la atención de } \\
\text { los hombres mostrando sus atributos } \\
\text { físicos. }\end{array}$ & $\begin{array}{l}\text { Todas las tecnocumbieras } \\
\text { muestras su cuerpo para } \\
\text { llamar la atención. }\end{array}$ \\
\hline $\begin{array}{l}\text { Vecinas de la familia } \\
\text { de Sharon }\end{array}$ & $\begin{array}{l}\text { Señoras de edad adulta, gordas y } \\
\text { descuidadas en su forma de vestir. Se } \\
\text { reúnen a criticar la vida de la familia de } \\
\text { Sharon principalmente. }\end{array}$ & Las vecinas son chismosas. \\
\hline Pilar & $\begin{array}{l}\text { Señora de edad adulta. Guardaba las } \\
\text { apariencias de un matrimonio estable, } \\
\text { pero tuvo una relación sentimental } \\
\text { con su chofer. }\end{array}$ & $\begin{array}{l}\text { Las mujeres de clase social alta } \\
\text { se involucran } \\
\text { sentimentalmente con su } \\
\text { personal. }\end{array}$ \\
\hline $\begin{array}{l}\text { Tere Bermeo } \\
\text { (Hermana de Sharon) }\end{array}$ & $\begin{array}{c}\text { Siempre ayudaba a su hermana Sharon } \\
\text { a hacer cosas a escondidas de su } \\
\text { madre. }\end{array}$ & $\begin{array}{l}\text { Las hermanas son } \\
\text { "alcahuetas". }\end{array}$ \\
\hline $\begin{array}{l}\text { Josefina (Prima de } \\
\text { Santanera) }\end{array}$ & $\begin{array}{l}\text { Dejó su pueblo para estar con su prima } \\
\text { Santanera. Ella le hace favores a su } \\
\text { prima y la ayuda a comprar alcohol } \\
\text { cuando ella se lo pide, por medio de } \\
\text { chantajes o por lástima. }\end{array}$ & $\begin{array}{l}\text { Las personas del campo son } \\
\text { ingenuas, sumisas y } \\
\text { manipulables. }\end{array}$ \\
\hline
\end{tabular}

Fuente: elaboración propia. ${ }^{*}$ Nota: personajes femeninos estudiados 
Se identificaron 5 estereotipos dentro de la telenovela (ver tabla 2), en donde todos son identificados por la audiencia y destacan: "las mujeres deben soportar infidelidades y maltratos de sus esposos para mantener su matrimonio" (48\%), "las mujeres que usan prendas cortas son más fáciles y accesibles" (46\%), y "es necesario que las tecnocumbieras usen ropa pequeña para llamar la atención del público" (44\%). Además, los estereotipos presentados en la telenovela tienen componentes que giran entorno a la hipersexualización de la mujer desde su vestimenta, patrones de comportamiento, contextos de sumisión y prejuicios que deslegitiman su éxito frente las capacidades que poseen.

Tabla 2. Estereotipos femeninos identificados en la telenovela Sharon, La Hechicera y que los informantes consideran ciertos en las tres localidades estudiadas de Ecuador

\begin{tabular}{|c|c|c|}
\hline Estereotipos femeninos identificados en la telenovela & $\mathbf{F}$ & $\mathbf{\%}$ \\
\hline $\begin{array}{c}\text { Las mujeres sensuales y con “buen cuerpo" tienen más } \\
\text { posibilidades de éxito. }\end{array}$ & 74 & $43 \%$ \\
\hline $\begin{array}{c}\text { Es necesario que las tecnocumbieras usen ropa pequeña } \\
\text { para llamar la atención del público. }\end{array}$ & 80 & $44 \%$ \\
\hline $\begin{array}{c}\text { Las mujeres que usan prendas cortas son más "fáciles” y } \\
\text { accesibles. }\end{array}$ & 60 & $46 \%$ \\
\hline $\begin{array}{c}\text { Todas las mujeres que han tenido éxito en el mundo del } \\
\text { espectáculo tuvieron algún tipo de relación sentimental } \\
\text { o sexual con sus socios }\end{array}$ & 84 & $34 \%$ \\
\hline $\begin{array}{c}\text { Las mujeres deben soportar infidelidades y maltratos de } \\
\text { sus esposos para mantener su matrimonio. }\end{array}$ & $48 \%$ \\
\hline
\end{tabular}

Fuente: elaboración propia. *Nota: personas encuestadas que sí vieron la telenovela Sharon La Hechicera.

Tabla 3. Características de los sujetos que observaron la telenovela en su totalidad y que fueron entrevistados a profundidad para conocer su percepción sobre la serie

\begin{tabular}{|c|c|c|c|c|}
\hline Nombre & Edad & Área & $\begin{array}{c}\text { Situación } \\
\text { económica }\end{array}$ & Nivel de estudios \\
\hline Entrevistado 1 & 18 años & Urbano & Media alta & Secundaria \\
\hline Entrevistado 2 & 21 años & Urbano & Media baja & Superior \\
\hline Entrevistado 3 & 22 años & Urbano & Media & Superior \\
\hline Entrevistado 4 & 26 años & Urbano & Media baja & Superior \\
\hline Entrevistado 5 & 30 años & Urbano & Media Baja & Secundaria \\
\hline Entrevistado 6 & 46 años & Urbano & Media & Secundaria \\
\hline Entrevistado 7 & 65 años & Rural & Baja & Primaria \\
\hline
\end{tabular}

Fuente: elaboración propia. ${ }^{*}$ Nota: personas encuestadas que sí vieron la telenovela Sharon La Hechicera.

Se aplicó la entrevista a profundidad a 9 participantes (ver tabla 3), 8 mujeres y 1 hombre, con edades comprendidas entre los 18 y 65 años. Todos se desarrollan en un 
contexto urbano, salvo una excepción. El nivel de instrucción académica está en secundaria (3 individuos) y superior (3 individuos).

Uno de los aspectos que interesan a los entrevistados es la vida de la cantante y su ánimo por superarse y salir de la pobreza (ver tabla 4). Además, "Santanera" es uno de los personajes favoritos de la teleserie porque cambia su vida y emprende un nuevo rumbo. Por tanto, establece un modelo de los propio y deseable en la categoría de ser un individuo bueno o malo, y la capacidad de enmienda. Entre los principales rasgos que identifican los participantes en sus entornos son la reproducción del machismo, la vestimenta, las frases que se incorporan en la cotidianidad y el uso de los estereotipos para categorizar a los sujetos de su entorno.

Tabla 4. Reconocimiento y apropiación de características de los personajes de la telenovela por parte de los entrevistados

\begin{tabular}{|c|c|c|c|c|}
\hline Entrevistados & $\begin{array}{c}\text { ¿Qué es lo que más } \\
\text { le llamó la atención } \\
\text { de la telenovela? }\end{array}$ & $\begin{array}{c}\text { ¿Cuál fue su } \\
\text { personaje favorito? } \\
\text { ¿Por qué? }\end{array}$ & $\begin{array}{c}\text { ¿Existe alguna } \\
\text { palabra, frase o } \\
\text { comportamiento } \\
\text { que recuerde o } \\
\text { haya puesto en } \\
\text { práctica a partir de } \\
\text { la visualización de } \\
\text { la telenovela? }\end{array}$ & $\begin{array}{l}\text { ¿Ha notado que } \\
\text { alguna persona de su } \\
\text { círculo social repitió } \\
\text { algún aspecto de la } \\
\text { telenovela (frases, } \\
\text { comportamientos, } \\
\text { creencias)? }\end{array}$ \\
\hline Entrevistado 1 & $\begin{array}{l}\text { Que Sharon era una } \\
\text { persona pobre, pero } \\
\text { pudo salir adelante } \\
\text { sola y lograr éxito. }\end{array}$ & $\begin{array}{l}\text { Santanera. Porque } \\
\text { ella cayó en los } \\
\text { vicios del alcohol, } \\
\text { pero logró cambiar } \\
\text { su vida para bien. }\end{array}$ & $\begin{array}{c}\text { Sí. Pusimos en } \\
\text { práctica la lección } \\
\text { de ser positivos y } \\
\text { pensar que se } \\
\text { puede salir adelante } \\
\text { a pesar de las } \\
\text { circunstancias. }\end{array}$ & No \\
\hline Entrevistado 2 & $\begin{array}{l}\text { Todo lo que tenían } \\
\text { que pasar las } \\
\text { tecnocumbieras } \\
\text { para llegar al| la } \\
\text { fama. Y cuando } \\
\text { alcanzaban el éxito } \\
\text { no sabían cómo } \\
\text { mantenerse, como } \\
\text { el caso de } \\
\text { Santanera. } \\
\text {-La ambición, que } \\
\text { mira los límites para } \\
\text { lograr lo que se } \\
\text { quiere. }\end{array}$ & $\begin{array}{l}\text {-Tere Bermeo. } \\
\text { Porque cuando } \\
\text { Sharon tenía } \\
\text { problemas, ella la } \\
\text { apoyaba, pero } \\
\text { también tenía su } \\
\text { carácter. }\end{array}$ & $\begin{array}{c}\text { Sí. Me gustaba } \\
\text { repetir Sharon La } \\
\text { Hechicera, tal como } \\
\text { lo decía la } \\
\text { protagonista. A } \\
\text { veces, me ponía a } \\
\text { practicar los pasos } \\
\text { de tecnocumbia que } \\
\text { hacía Sharon. }\end{array}$ & $\begin{array}{l}\text { Sí. Con mis amigas } \\
\text { repetimos frases o yo } \\
\text { cantaba las canciones } \\
\text { de Sharon y ellas } \\
\text { bailaban. } \\
\text { También empecé a } \\
\text { molestar a mis } \\
\text { compañeras cuando } \\
\text { se vestían sexy y las } \\
\text { llamaba "divas" o } \\
\text { "tecnocumbieras". }\end{array}$ \\
\hline Entrevistado 3 & $\begin{array}{l}\text { Me gustó cómo hizo } \\
\text { todo lo posible para } \\
\text { alcanzar sus } \\
\text { objetivos. Ella } \\
\text { buscaba } \\
\text { oportunidades en }\end{array}$ & $\begin{array}{l}\text { Santanera. Porque } \\
\text { aprendió a vivir la } \\
\text { vida y dejar los } \\
\text { malos caminos. }\end{array}$ & No & $\begin{array}{l}\text { Sí. A una amiga le } \\
\text { gustaba el personaje } \\
\text { "Frijolito" y repetía } \\
\text { mucho sus frases, } \\
\text { como "Busca nuevas } \\
\text { oportunidades", ya }\end{array}$ \\
\hline
\end{tabular}


Nicole Silva-Gaviles, Bryan Vaca-Rivera, Juan Arrobo-Agila y Santiago Bravo-Sánchez

\begin{tabular}{|c|c|c|c|c|}
\hline & $\begin{array}{l}\text { cualquier lugar para } \\
\text { cantar. }\end{array}$ & & & $\begin{array}{c}\text { que él siempre } \\
\text { apoyaba a Sharon. }\end{array}$ \\
\hline Entrevistado 4 & $\begin{array}{l}\text { Conocer la vida de } \\
\text { Sharon y su } \\
\text { participación con } \\
\text { muchos artistas } \\
\text { nacionales. }\end{array}$ & $\begin{array}{l}\text { Santanera. Porque } \\
\text { tenía una } \\
\text { trayectoria } \\
\text { importante, pero } \\
\text { sus adicciones la } \\
\text { hicieron pasar de } \\
\text { ser una diva a } \\
\text { comer de la basura. } \\
\text { Pero cambió su vida } \\
\text { y enfrentó sus } \\
\text { problemas. }\end{array}$ & No & No \\
\hline Entrevistado 5 & $\begin{array}{l}\text { Cómo recrearon la } \\
\text { muerte de Sharon. }\end{array}$ & $\begin{array}{l}\text { Sharon. Porque vi la } \\
\text { telenovela, para } \\
\text { conocer más sobre } \\
\text { su vida y cómo } \\
\text { ocurrió su trágica } \\
\text { muerte. }\end{array}$ & $\begin{array}{l}\text { No. Esta novela no } \\
\text { tenía tantas frases } \\
\text { como para } \\
\text { recordarlas, a } \\
\text { diferencia de otros } \\
\text { programas que se } \\
\text { daban en el mismo } \\
\text { canal. }\end{array}$ & $\begin{array}{c}\text { Sí. En ocasiones } \\
\text { comentaban la forma } \\
\text { de vestir de los } \\
\text { personajes. Por } \\
\text { ejemplo, cuando } \\
\text { veíamos al personaje } \\
\text { de “Pilar" teníamos la } \\
\text { intención de copiar su } \\
\text { forma de vestirse o } \\
\text { mandarnos a hacer } \\
\text { ropa como la que } \\
\text { usaba ella. }\end{array}$ \\
\hline Entrevistado 6 & $\begin{array}{c}\text { Los protagonistas se } \\
\text { supieron } \\
\text { desenvolver en cada } \\
\text { uno de sus papeles, } \\
\text { volviéndola muy } \\
\text { llamativa para los } \\
\text { espectadores. }\end{array}$ & $\begin{array}{l}\text { Mandrake. Porque } \\
\text { logró encarnar a } \\
\text { una persona mala y } \\
\text { machista a la } \\
\text { perfección. }\end{array}$ & $\begin{array}{l}\text { Solo observé la } \\
\text { novela como } \\
\text { manera de } \\
\text { distracción, así que } \\
\text { no adopté ninguna } \\
\text { clase de expresión o } \\
\text { comportamiento } \\
\text { que ahí se podían } \\
\text { observar }\end{array}$ & $\begin{array}{c}\text { Muchas veces se } \\
\text { puede observar el } \\
\text { machismo presente } \\
\text { en el círculo social que } \\
\text { me rodea. No era tal } \\
\text { cual se puede } \\
\text { observar en las } \\
\text { actuaciones que } \\
\text { realizaban los } \\
\text { personajes, pero } \\
\text { siempre el machismo } \\
\text { está presente y esa } \\
\text { situación era una de } \\
\text { las temáticas de la } \\
\text { telenovela. }\end{array}$ \\
\hline Entrevistado 7 & $\begin{array}{l}\text { La compresión y el } \\
\text { apoyo tanto de la } \\
\text { mamá como de la } \\
\text { hermana hacia } \\
\text { Sharon. Se ve } \\
\text { reflejado cómo la } \\
\text { artista logró las } \\
\text { cosas por el apoyo } \\
\text { de cada una de las } \\
\text { personas que la } \\
\text { rodeaban. }\end{array}$ & $\begin{array}{c}\text { Santanera. Porque } \\
\text { se logra observar el } \\
\text { sufrimiento moral } \\
\text { que tiene, además } \\
\text { de las humillaciones } \\
\text { que pasa. }\end{array}$ & $\begin{array}{l}\text { Sí. Se puede adoptar } \\
\text { de alguna forma el } \\
\text { comportamiento y } \\
\text { la forma de actuar. } \\
\text { Es decir, ver las } \\
\text { actitudes de } \\
\text { comprensión y } \\
\text { ayuda hacia otras } \\
\text { personas que } \\
\text { algunos personajes } \\
\text { muestran y que se } \\
\text { deberían seguir. }\end{array}$ & No \\
\hline
\end{tabular}

Fuente: elaboración propia. ${ }^{*}$ Nota: personas encuestadas que sí vieron la telenovela Sharon La Hechicera. 


\section{DISCUSIÓN}

Los estereotipos representados en los personajes de la telenovela Sharon La Hechicera fueron identificados a través del complemento de la actuación con el aspecto físico con que se caracterizó a cada personaje. Y esto también puede evidenciarse en la investigación de Tatiana Hidalgo-Marí (2019, p. 701), donde explica que la "mujer fatal" (la villana de una telenovela) es representada por "un personaje femenino cautivador, erótico y seductor, que utiliza su atractivo como herramienta de subsistencia y superación personal". En el caso de Sharon La Hechicera, los personajes antagónicos debían "valerse" de su aspecto físico para conseguir sus objetivos.

Para Esteban (2013) los espectadores son capaces de adoptar las conductas, que ven en las telenovelas, haciéndolas parte de ellos y poniéndolas en práctica en su contexto. Esto puede evidenciarse en las entrevistas, donde 3 mujeres afirmaron haber reproducido conductas o frases que vieron en la telenovela Sharon La Hechicera, mientras que 3 entrevistadas también manifestaron haber visto reproducirse conductas de este melodrama dentro de su contexto.

Una reproducción de conductas en un contexto no puede ser invisibilizado e ignorado. Tal como lo manifiesta Mazziotti, citado por Hidalgo-Marí (2019), la telenovela es uno de los productos televisivos más reconocidos en Latinoamérica. Su discurso cultural puede afectar a la construcción social, capaz de afectar la imagen femenina y condicionarla al ideal de un melodrama.

La capacidad crítica puede ayudar a la interpretación de estereotipos. Las personas con mayor preparación académica y clase económica más alta no demostraron el mismo interés por visualizar la telenovela, que una persona que poseía menores niveles de estudio y clase económica. Esto puede justificarse con la teoría de Caldevilla (2010), donde manifiesta que la ficción televisiva construye una realidad que logre que los espectadores sientan mayor atracción hacia los personajes cuando se identifican con sus cualidades. Así que al tratarse de una telenovela que se desarrolla en un contexto de clase baja, los espectadores que sienten mayor atracción por el contenido también 
pertenecen a una clase baja. Es decir, mientras existe más identificación entre un espectador y un personaje, puede existir mayor influencia.

En el caso de las mujeres, se evidencia el deseo de emular a personajes femeninos que vieron en la telenovela, como "Sharon", "Santanera" y "Pilar". Según Padilla (2006), las supuestas realidades son acogidas por las audiencias y forman estereotipos sin fundamentos. El desconocimiento o confusión de los contenidos presentados en una realidad imaginaria, en este caso las telenovelas, podría aumentar la posibilidad de aceptación de los estereotipos femeninos receptados, relacionados con características físicas, como la ropa y el cuerpo, y por situaciones sociales que se han difundido a través del tiempo.

Los estereotipos femeninos en la telenovela actúan como una representación de una realidad, que se identifica y generaliza sobre atributos o características que ya han sido previamente establecidos por una sociedad. Es interesante revisar que los estereotipos que la mayoría de encuestados determinaron como ciertos en la sociedad ecuatoriana son: "Las mujeres que usan prendas cortas son más fáciles y accesibles", "Las mujeres sensuales y con buen cuerpo tienen más posibilidades de éxito" y "Las mujeres deben soportar infidelidades y maltratos de sus esposos, para mantener su matrimonio". Según Hernández (2006), los estereotipos crean una percepción de género interiorizada de la cual se apropian y conlleva a una representación de la realidad como las acciones, pensamientos y comportamientos de los sujetos. En esta investigación, al ser estos estereotipos los más relevantes para los ecuatorianos, se podría cuestionar cuánta influencia ha tenido el contenido de esta telenovela en la sociedad ecuatoriana al transmitir estereotipos.

Por otra parte, las características corporales expresadas en los medios son uno de los factores más llamativos y aceptados como ideales por las audiencias. Bourdieu (2007) expone que las personas se construyen en la sociedad a partir de la propia percepción del cuerpo. Por ello, las mujeres aceptan estereotipos femeninos, relacionados con la forma de vestir, movimiento corporal, moral, pudor y otras dimensiones que se presentan en la realidad. En las entrevistas realizadas, las mujeres expresaron su deseo 
de parecerse a personajes como "Pilar" por su estilo, a tal punto de enviar a confeccionar prendas de ropa como las que el personaje usaba.

Finalmente, es necesario destacar el favoritismo de la audiencia por diferentes personajes, ya que este aspecto podría abrir nuevas investigaciones. Es decir, por qué un espectador puede preferir a un personaje y a otro no. Esta relación podría determinarse por el actor que representa al personaje, la identificación que tiene el espectador o el protagonismo que tiene el personaje dentro de la telenovela.

\section{CONCLUSIONES}

A partir de la investigación realizada se comprobó que los estereotipos encarnados en los personajes de una telenovela y su visualización permiten la instauración de estos en el imaginario de la audiencia y puede condicionar la repetición de estos comportamientos, características y mensajes emitidos.

En el imaginario colectivo de la sociedad ecuatoriana es fácilmente identificable el estereotipo construido desde el vestuario de las mujeres que da la categoría de "fáciles" y "accesibles" por el uso de prendas cortas. Este junto a "las mujeres deben soportar infidelidades para mantener apariencias" fueron los más aceptados por los encuestados. La mayoría de mujeres que afirmaron estos conceptos, manifestaron considerarlos capaces de influir en la sociedad.

Los datos reflejan que las mujeres han sentido preferencia o rechazo por los diferentes personajes de la telenovela. Y esta respuesta de la audiencia ha sido influenciada por el aspecto físico de los personajes, como su cuerpo, vestimenta o rol dentro de la telenovela.

\section{REFERENCIAS BIBLIOGRÁFICAS}

Ahmed Ali, F., Martín Galán, J. I. y Nos Aldás, E. F. (Eds.). (2011). Comunicación para la paz en acción: Periodismos, conflictos, alfabetización mediática y Alianza de Civilizaciones (Vol. 8). Castellón: Publicacions de la Universitat Jaume I. 
Álvarez, H. G. (2008). Vivir con la televisión. 30 años de análisis de cultivo. Anagramas rumbos y sentidos de la comunicación, 7(13), 91-106.

Amigo, B., Bravo, M. C. y Osorio, F. (2014). Telenovela, recepción y debate social. Cuadernos. info, (35), 135-145.

Bautista, J. y Dolores, M. (2008). Recepción de telenovelas y perspectiva de género. Comunicar, 16(31), 673-679. Recuperado de https://www.revistacomunicar.com/index.php?contenido=detalles\&numero=31\&artic ulo $=31-2008-90$

Bonavitta, P. y Garay, J. (2011). De estereotipos, violencia y sexismo: la construcción de las mujeres en los medios mexicanos y argentinos. Anagramas, 9(18),15-30.

Bourdieu, P. (2007). El sentido práctico. Buenos Aires: Siglo XXI Editores Argentina S.A. Caldevilla, D. (2010). Estereotipos Femeninos en Series de TV. CHASQUI, 111, 73-78. Esteban, M. (2013). Antropología del cuerpo: Género, itinerarios corporales, identidad y cambio. Barcelona: Ediciones Bellaterra

Hernández, Y. (2006). Acerca del género como categoría analítica. Nómadas, 13 (1), pp. $110-121$.

Hidalgo-Marí, T. (2019). Perversas, seductoras y villanas: La construcción de la mujer fatal en la telenovela latinoamericana. Historia y Comunicación Social, 24(2), 699-712. https://doi.org/10.5209/hics.66309

León, C. y Suing, A. (2016). La televisión ecuatoriana: pasado y presente. Razón y Palabra, 20(93), 135-152. Recuperado de https://www.revistarazonypalabra.org/index.php/ryp/article/view/8

Martínez, A. (21 de junio del 2019). Estas son las imágenes de lo que será Sharon 2 antes del estreno. Metro Ecuador. Recuperado de https://www.metroecuador.com.ec/ec/entretenimiento/2019/06/21/imagenessharon-2-estreno.html 
OBITEL (2011). Coordinadores: Orozco, G., y M. Inmacolata. Calidad de la ficción televisiva y participación transmediática de las audiencias. Porto Alegre- Brasil.

Padilla, M. (2006). Una nueva socialité llegó: historia de la recepción televisiva en la ciudad de aguacalientes. Comunicación y sociedad, 7, 101-128.

Pérez, M. y Leal, S. (2017). Las telenovelas como generadoras de estereotipos de género: el caso de México. Anagramas Rumbos y Sentidos de la Comunicación, 16(31), 167-185.

Perosanz, J. J. I., del Río Pereda, P., Álvarez, A., García, L. C., García, F. J., Garrachón, L., y Yáñez, E. (1998). Indicadores culturales y construcción de estereotipos en films de acción. Comunicación \& cultura, 5, 43-56.

Piovani, J. (2018). Reflexibilidad en el proceso de investigación social: entre el diseño y la práctica, 74-92. En J. I. Priovani y L., Muñiz (Coord.), ¿Condenados a la reflexibilidad? Apuntes para repensar el proceso de investigación social. Clacso, Editorial Bilblos.

Santos, J., Pi, P., y Rausky, M. (2018). Métodos mixtos y reflexibilidad: explorando posibles articulaciones. En Juan Ignacio, Priovani y Leticia, Muñiz (Coord.). ¿Condenados a la reflexibilidad? Apuntes para repensar el proceso de investigación social (pp. 254-283). Buenos Aires: Editorial Bilblos.

Valles, M. (1999). Técnicas cualitativas de investigación social: reflexión metodológica y práctica profesional. Madrid: Editorial Síntesis. 